\title{
Utilization of waste wool fibers for fabrication of wool powders and keratin: a review
}

\author{
Chunhua Zhang ${ }^{1,2,3}$, Liangjun Xia ${ }^{1,4}$, Jiajing Zhang ${ }^{1}$, Xin Liu' ${ }^{1,2}$ and Weilin $X u^{1 *}$
}

\begin{abstract}
Wool fiber contains approximately 95\% keratinous proteins, which is one of the most abundant sources of structural protein. However, a large amount of wool waste is underutilized. Developing appropriate approaches to recycle wool waste and produce value-added products is vital for sustainable development and reducing environmental burden. Thus, this paper reviews the mechanical methods of fabricating wool powder, including pan milling, combined wet and air-jet milling, steam explosion, freeze milling, and three-stage milling. The influencing factors of shape and size, structure, and properties are highlighted to overview of the possible controlling methods. Then, this review summarizes various chemical methods for the extraction of wool keratin, underlining the dissolution efficiency and the structure of wool keratin. Furthermore, the application of reused wool particles in textile, biosorbent, and biomaterials are also reported. Finally, several perspectives in terms of future research on the fabrication and application of wool particles are highlighted.
\end{abstract}

Keywords: Wool waste, Powder, Keratin, Milling method, Textile, Biomaterial

\section{Introduction}

Wool is a biodegradable and biocompatible natural fiber that has attracted considerable attention for use in textiles and various technological fields due to its outstanding properties, such as specific structure, high moisture regain, excellent resiliency, good elasticity and good insulation capacities, low heat conductivity, and excellent affinity for dyestuffs [1]. More than 2.5 million tons of wool are produced annually worldwide [2]. Waste wool mainly comprises by-products of wool fiber subjected to textile processing, poor-quality raw wool that is not fit for spinning, and other secondary waste that is generally obtained in the textile industry. However, large amounts of wool waste are dumped in landfills or burnt, which may contribute to the pollution of the environment. Rising concern for the environment and growing

\footnotetext{
* Correspondence: weilin_xu0@163.com

${ }^{1}$ State Key Laboratory of New Textile Materials and Advanced Processing

Technologies, Wuhan Textile University, Wuhan 430200, China

Full list of author information is available at the end of the article
}

demand for safe and sustainable bio-based materials are prompting the search for improved recycle methods of wool waste.

Several reviews on fabrication methods and applications of wool particles have been reported in recent years. Patil et al. [3] reviewed the direct and indirect routes to fabricate the ultrafine particles from protein fibers. They also presented the applications of protein fiber particles. K. Donato et al. [4] introduced the keratin and its-based biomaterials. Karthikeyan et al. [5] reported the industrial applications of keratins extracted from feathers, hair, wool, and horn. Gosh et al. [6] summarized the keratin-based materials for toxic pollutants absorption. Shavandi et al. [7] discussed the advantages and limitations of the major methods for extracting keratin, including reduction, oxidation, microwave irradiation, alkali extraction, steam explosion, sulfitolysis, and ionic liquids. Furthermore, they reviewed various modification methods of wool fibers and the recent keratin-based thermoplastic biocomposites fabrication 
methods, including intermixed blending, and melt processing $[8,9]$.

In this review, we focused on the environmentally friendly methods to recycle wool fiber. Firstly, the structure and properties of wool powders fabricated using different methods, including pan milling, combined wet and air-jet milling, steam explosion, freeze milling, and three-stage milling, were compared. Secondly, the traditional methods for extraction wool keratin were summarized. The limitations of traditional chemical methods to extract wool keratin have inspired researchers to develop simple and eco-friendly processing methods. The extraction efficiency of wool keratin using a series of green ionic liquids (ILs) and deep eutectic solvent (DEP) solvent are highlighted. In addition, the promising applications in the textiles, biosorbents, cosmetic, and biomaterials are reviewed. Finally, the problems and challenges of fabrication methods as well as the applications for wool particles were discussed.

\section{Preparation methods of wool particle}

Recovered wool waste is considered a "rich" material owing to its composition and properties [10]. Ideally, wool particles should be fabricated via a technology that does not produce hazardous waste. To this end, various mechanical and chemical methods have been developed. This section presents a detailed overview of the utilization of wool waste.

\subsection{Mechanical method}

Mechanical methods are effective for fabricating various wool powders of different sizes and shapes. Generally, these methods are characterized by short durations as well as low-cost and are suitability for mass production. Moreover, these methods can reuse all the wool waste generated at different stages of the textile lifecycle. Micro and nanoparticles produced by mechanical methods can maintain the natural microstructure and high crystallinity of the wool fiber. Among various mechanical methods, pan milling, combined wet and air-jet milling, steam explosion, freeze milling, and three-stage milling have been commonly used to fabricate wool powders. Figure 1 shows the corresponding preparation process.

\subsubsection{Pan milling}

According to $\mathrm{Xu}$ et al. [11, 12], needle-like wool powder with an average diameter of $2 \mu \mathrm{m}$ can be obtained after grinding wool fiber for only $3 \mathrm{~h}$ using a home-made machine with two special milling pans [13], one of which has a concave surface, and the other, a convex surface. The two milling pans exhibited low heat generation and high anti-abrasion properties, preventing heat accumulation in the grinding zone. This approach has been used for the fabrication of other fiber powders, including fibroin powder, down powder, leather powder, and cellulose powder at room temperature without additional cooling processes [14-17]. The shape and size of the wool powders are directly determined by the grinding

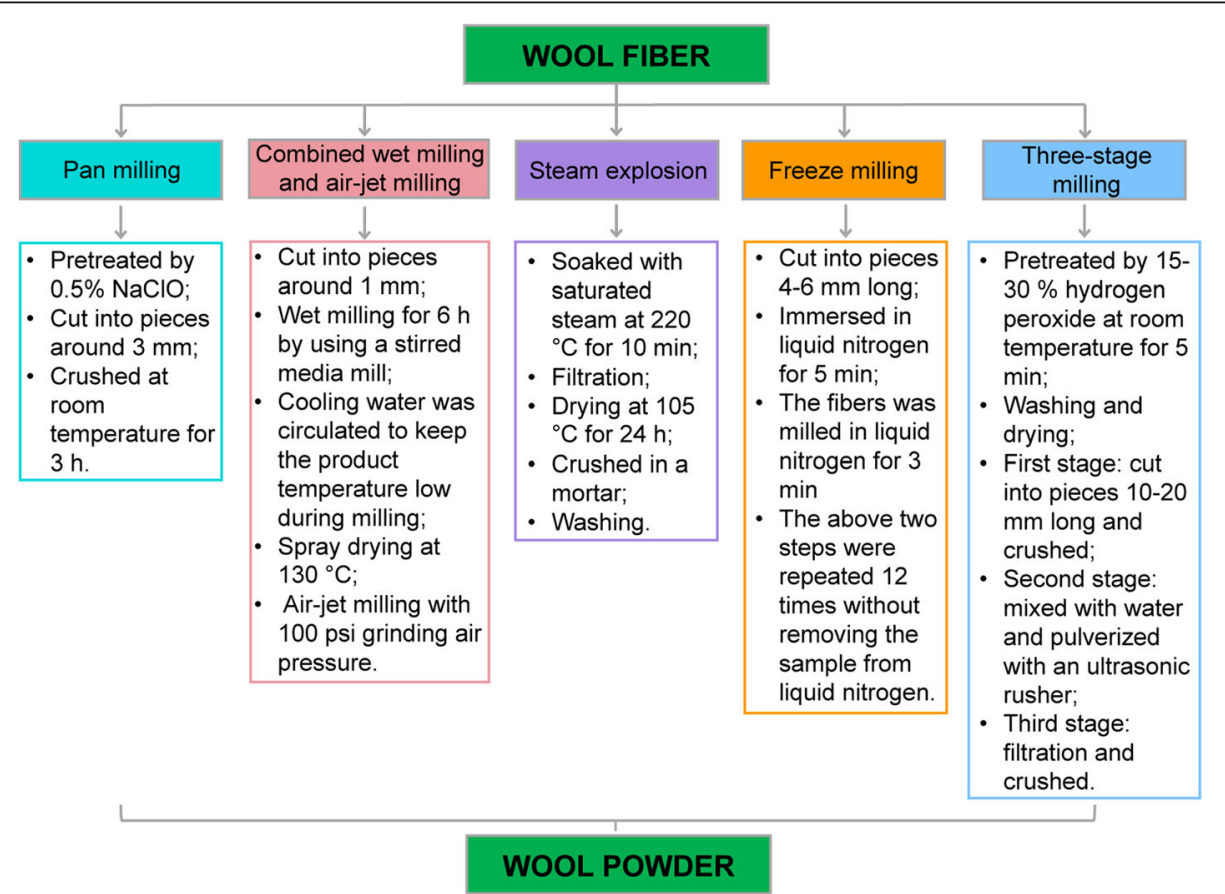

Fig. 1 Mechanical methods of fabricating wool powders 
time. The wool powder prepared using a grinding time of $5 \mathrm{~min}$ exhibited the original outline of the wool fiber. After grinding for $0.5 \mathrm{~h}$, the amorphous region was first destroyed, leading to the formation of wool powder with a small diameter. As the grinding time was increased, certain crystals of the wool fiber were also destroyed, slightly decreasing the crystallinity. Additionally, $\mathrm{Xu}$ et al. [12] compared the influence of the grinding time on thermal properties obtained using this technique. They found that as the grinding time increased, the wool powder's affinity to water increased. Furthermore, the temperature for the crystal cleavage and the destruction of the crosslinks also increased. The fine wool powder, with improved thermal stability, had advantages in polymer-based applications.

From an industrial perspective, the fabrication of wool powder by pan-milling is convenient, simple, and economical since it allows the rapid production of powders at room temperature. This method solves the issue of uneven particle size distribution, commonly observed when using mechanical methods. This effective fabrication strategy exhibits potential for the fabrication of fine powder. The approach, however, requires a special machine.

\subsubsection{Combined wet milling and air-jet milling}

Rajkhowa et al. $[18,19]$ obtained ultrafine wool powder using a combination of two sets of milling methods, i.e., wet and air-jet milling. The typical wool powder fabrication process is as follows. First, wool fibers are chopped to a length of $1 \mathrm{~mm}$. The snippets are immersed in water for $6 \mathrm{~h}$, for wet milling. Circulating cooling water $\left(18^{\circ} \mathrm{C}\right)$ is used to keep the product temperature low during the milling process. After wet milling, the wet powders were spray-dried at $130^{\circ} \mathrm{C}$. Finally, the resulting dried wool particles are ground using an air-jet milling machine with a grinding air pressure of 110 psi.

The wet milling time and air-jet milling process can significantly affect the size and morphology of the wool powders, resulting in the formation of different morphologies of wool powders, as shown in Fig. 2. SEM images show that the particle size of the wool powder is reduced by increasing the wet milling time. After wet milling for $5 \mathrm{~h}$, the wool powder appears to be aggregated. The air jet milling process is then used to improve the separation of particles through the application of external high pressure. The final prepared wool powder shows a considerable reduction in median size (from $4.0 \mu \mathrm{m}$ to $1.5 \mu \mathrm{m}$ ) using air-jet milling, as shown in Fig. 2d. Brunauer-Emmett-Teller (BET) analysis of the wool powder demonstrated that the surface area of ultrafine wool particles is 700 times higher than the wool fiber. Therefore, it is necessary to separate the wool particle aggregates by the air-jet milling method.

Faruque et al. [20] fabricated alpaca powders using this method. The average diameter of the as-prepared particles was $2.5 \mu \mathrm{m}$ without using any chemicals in the

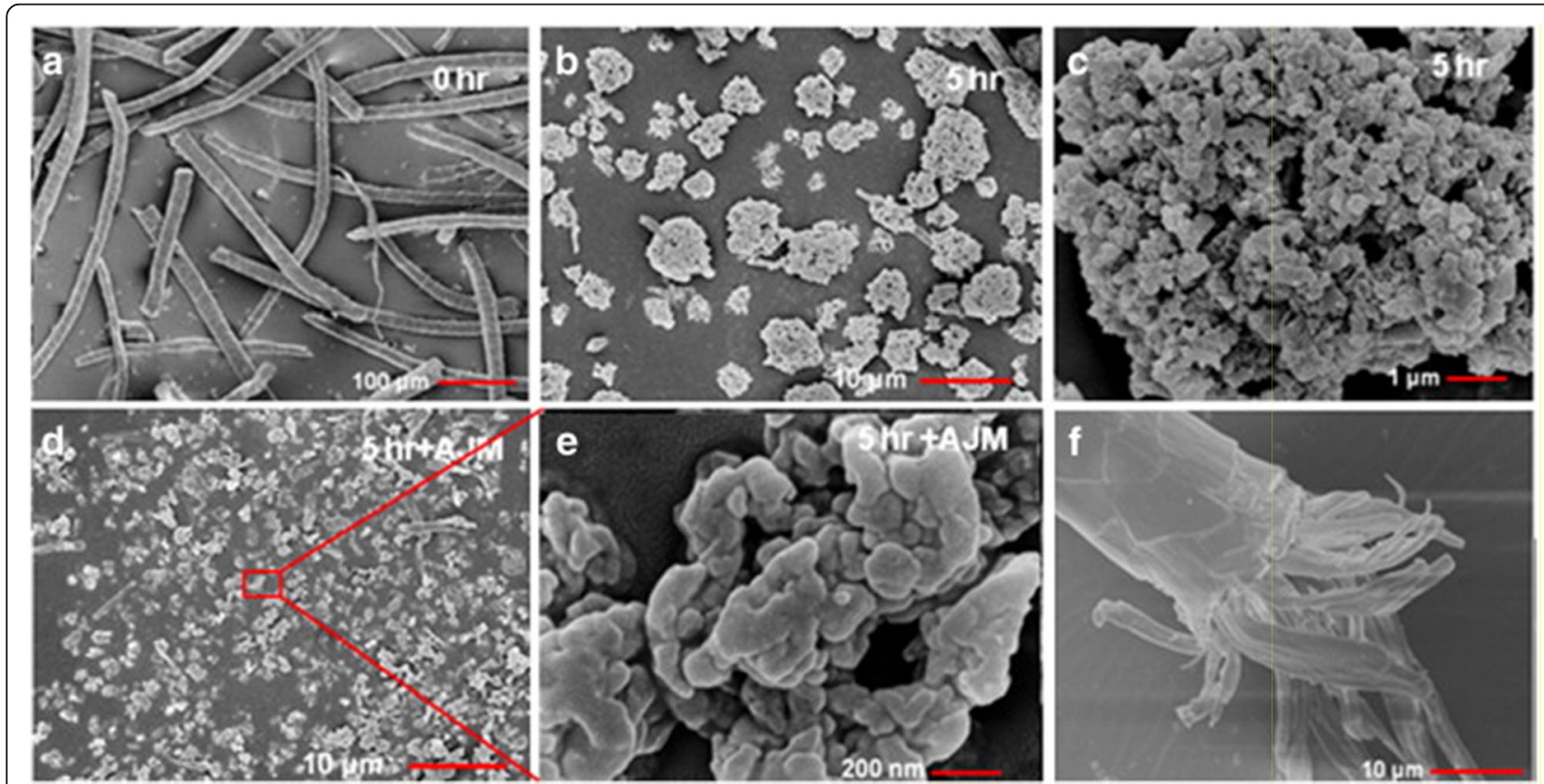

Fig. 2 SEM images of wool powder using combined wet milling and air-jet milling methods. a snippets; $\mathbf{b}$ after $5 \mathrm{~h}$ wet milling followed by drying; c magnified image of $\mathbf{b}$; $\mathbf{d}$ air jet milling of $\mathbf{b}$; e magnified image of $\mathbf{d}$; $\mathbf{f}$ fractured wool fiber. Reprinted with permission from Reference [18]. Copyright 2012, Elsevier 
pretreatment and powder fabrication processes. X-ray diffraction (XRD) analysis demonstrated that the crystallinity of the prepared alpaca powders decreased with increasing milling time. Moreover, the differential scanning calorimetry (DSC) and thermogravimetric analysis (TGA) tests revealed that the thermal properties of the powders were similar to that of the alpaca fibers.

Using a similar method, Patil et al. [21] compared the morphology and surface properties of cashmere guard hair powders, with and without acid hydrolyzed guard pretreatment. They found that the average diameter of the as-prepared powder reduced from $2.32 \mu \mathrm{m}$ to $0.46 \mu \mathrm{m}$ when the cashmere guard hair was subjected to acid hydrolysis pretreatment. The particle size and shape of the powder were greatly affected by acid hydrolysis during dry air jet milling but not during wet attritor milling. Additionally, the hydrolysis induced a more porous structure, leading to an increased BET surface.

For the preparation of micron-scale powder, combined wet and air-jet milling does not require chemical pretreatment, and thus, avoids chemical degradation of the protein structure. This is a huge advantage. The air-jet milling process can fabricate well-separated fine particles, but the machine requires high pressure.

\subsubsection{Steam explosion}

Tonin et al. [22] investigated a rapidly developing technique for the fabrication of wool powder. The wet wool fibers were soaked with saturated steam at $220^{\circ} \mathrm{C}$ for 10 min. The slurry was then filtered, and two phases (wet solid-state and liquid phase) were obtained. The wet solid was dried at $105^{\circ} \mathrm{C}$ and then ground into short wool fragments or shapeless aggregates. Additionally, sediment in the liquid phase was separated using a centrifugal force. The wool powder with spherical morphology (with a diameter in the range $0.5-3.0 \mu \mathrm{m}$ ) was observed in the dried sediment, which was attributed to the external thermal-induced shrinkage of protein. The obtained wool powders exhibited more $\beta$-sheet and disordered structures.

This approach showed the conversion of the wool fiber under strong physical conditions, confirming the cleavage of the disulfide bonds in the wool fiber without the addition of harmful chemical agents. The main advantage of this method is the rapid and simple production process without the need of additional toxic chemical agents. However, the size of $62.36 \mathrm{wt} \%$ solid particle is considered too large. Thus, this green process has been considered suitable for the rapid pretreatment of wool fiber.

\subsubsection{Freeze milling}

The high temperature during the milling process oxidizes the powder easily. Therefore, Hassabo et al. [23,
24] presented a systematic study on the fabrication of wool powder using a freezer/mill machine using liquid nitrogen. The freezing and crushing time under liquid nitrogen in the milling process were optimized. The size of the wool powder depended significantly on the crushing time. The results showed that the fabrication of wool powder, in the size of $60-80 \mu \mathrm{m}$, is optimized when the freezing time is $5 \mathrm{~min}$, crushing time is $3 \mathrm{~min}$, and number of cycles is 12 . In the liquid nitrogen, the oxidation is hindered, resulting in white wool powder. Raman spectroscopy showed that the freeze milling process does not affect the chemical structure of the wool. Additionally, the wool powder retained the thermal properties of the wool fibers. The freeze milling method can preserve the structure of the wool fiber; further, this method is considered suitable for the production of high valueadded products, or as a pretreatment method, owing to the use and safety of liquid nitrogen in the grinding process.

\subsubsection{Three-stage milling}

As expected, soft viscoelastic fibers are difficult to mill into nano-powder. Thus, the pretreatment for wool fiber is an effective manner to produce nanoscale powder. Cheng et al. [25] developed a pretreatment approach for wool fibers using a hydrogen peroxide solution. This included three main stages, as indicated by its name.

2.1.5.1 First stage After pretreatment, the disulfide bond of the wool fiber was gradually oxidized. First, the wool was milled into a combination of rod-like particles of around $300 \mu \mathrm{m}$, and then into superfine powder, smaller than $10 \mu \mathrm{m}$.

2.1.5.2 Second stage Large wool particles were pulverized with an ultrasonic crusher to obtain wool powder with a diameter of $0.1-7 \mu \mathrm{m}$.

2.1.5.3 Third stage The fine wool powder was crushed into nanoscale spherical powder (with a diameter less than $100 \mathrm{~nm}$ ) using a nanocolliding machine. The spherical nanoscale wool powder produced by this method exhibited decreased crystallinity and improved amounts of the secondary amine groups. Additionally, no evident changes were observed in the chemical structure of the wool particles.

As described above, small-sized wool powder particles, with spherical morphologies, are obtained using the three-stage milling method. This method of fabricating wool nanopowder combines the pretreatment and design of the milling parameters effectively. 


\subsection{Chemical method}

\subsubsection{Oxidative and reductive methods}

Wool fiber is a fibrous protein that consists of approximately 95\% pure keratin [10]. The presence of a high degree of disulfide cross-linkages, ionic and hydrogen bonds and other bonds in wool keratin constraints the polypeptide backbone. Traditional keratin extraction methods of wool fiber, including reduction, oxidation, and sulfitolysis, utilize the different properties of oxidative and reductive agents to cleave disulfide bonds. The extraction mechanisms are shown in Fig. 3.

For decades, oxidation methods have been performed to extract keratin. The commonly used oxidative agent is peracetic acid and performic acid. Pakkaner et al. [26] reported the synthesis of wool keratin through peracetic acid oxidation. In a typical process, $2 \% \mathrm{w} / \mathrm{v}$ wool/peracetic acid was dissolved at $37^{\circ} \mathrm{C}$. The oxidized fibers wre then treated with a $100 \mathrm{mM}$ tris-base solution, at $\mathrm{pH}$ 10.5 , for $2 \mathrm{~h}$. Finally, the keratin solution was centrifugated, dialyzed, and freeze-dried. The spherical nanoparticles, in sizes ranging from 15 to $100 \mathrm{~nm}$, were obtained at low protein concentration $(5 \mathrm{mg} / \mathrm{ml})$ in solution. The molecular weights (MWs) of water-soluble oxidized keratin proteins are between 23 and $33 \mathrm{kDa}$. Buchanan et al. [27] used performic acid to fabricate keratin containing cysteine and cysteic acid with low MWs.

The main advantage of the oxidation methods is that the protein can be separated into $\alpha, \beta$, and $\gamma$ keratose, based on their different solubility at different $\mathrm{pH}$ [28].
Furthermore, the obtained keratose exhibited high content of cysteine-S-sulfonated residues. The disadvantage of this method is the low extraction yield and the high process time.

As shown in the Fig. 3, the disulfide bonds can be disrupted using thiol and sulfite. The commonly used thiol is thioglycolate acid, and mercapto-ethanol (MEC). Yamanaka et al. [29] extracted soluble wool keratin using $0.2 \mathrm{M}$ thioglycolic acid at $30^{\circ} \mathrm{C}$ at a $\mathrm{pH}$ in the range 11-13. They reported that the yield increased with the increase in $\mathrm{pH}$ and reaction time $(\mathrm{pH}<13)$. The wool keratin maintains the chemical structure of wool.

Recently, Fitz-Binder et al. [30] were the first to obtain wool keratin using the combination of calcium chloride $\left(\mathrm{CaCl}_{2}\right)$-water-ethanol solvent and thioglycolic acid. The effect of $\mathrm{pH}$, reaction time and temperature of the dissolution of wool fiber were investigated. The results highlighted that the dissolution was optimal when $\mathrm{pH}=$ 7.0 , time $=2 \mathrm{~h}$, and temperature $=60{ }^{\circ} \mathrm{C}$. Up to $70 \%$ of the wool keratin was dissolved in the solvent using this method. The advantage of the mixed solution used in this approach is that they can reduce the risk of hydrolytic degradation of wool keratin. After the formation of wool keratin, the keratin solution directly solidified under the heat-press, enabling the formation of a keratin composite.

Yamauchi et al. [31] obtained wool keratin using MEC. The typical process of thiol reduction preparation used is as follows: The cleaned wool was mixed with $7 \mathrm{M}$ (a)

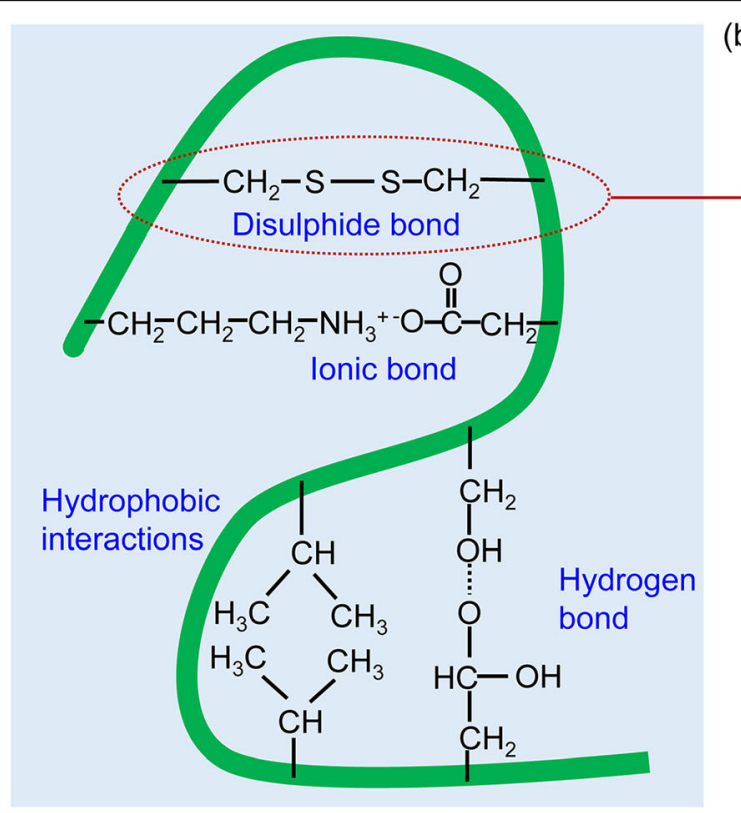

Polypeptide backbone (b)

$$
\text { Oxidation method }
$$

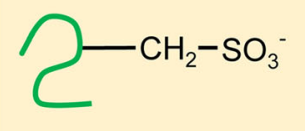

Reduction method

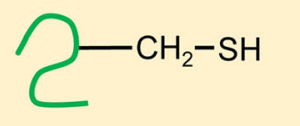

Sulfitolysis method

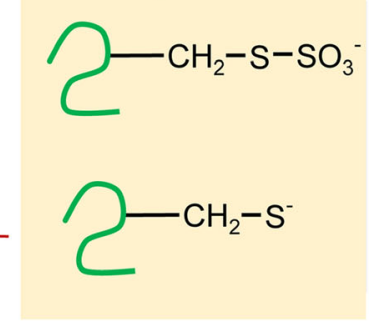

Fig. 3 (a) Schematic diagrams of inter-molecular and intra-molecular bonding of keratin; (b) Keratin extraction mechanism by oxidation method, reduction method, and sulfitolysis method, respectively 
urea, sodium dodecyl sulfate (SDS), and MEC at $50{ }^{\circ} \mathrm{C}$ for $12 \mathrm{~h}$. The aqueous was maintained at neutral $\mathrm{pH}$. Next, the solution was dialyzed to get regenerated wool keratin. They found that the surfactant accelerated the wool keratin extraction, preventing the aggregation of keratin polypeptide chains during dialysis. The MWs of wool keratin was in the range $52-69 \mathrm{kDa}$.

The preparation of wool keratin using thiol is highly efficient at low temperatures. The regenerated keratin can maintain the original structure of wool with a high yield. However, the thiol is harmful to handle. Sodium sulfite, a green chemical that can breakdown disulfide bonds, was used to replace thiols. The mechanism of keratin dissolution using sulfitolysis is shown in Fig. 3 Shavandi et al. [32] dissolved wool using $8 \mathrm{M}$ urea and sodium metabisulfite at $60^{\circ} \mathrm{C}$ in $10 \mathrm{~h}$. The wool keratin powder was then obtained by filtration, dialysis, and freeze-drying. The keratin extraction yield $(41 \%)$ by sulfitolysis method was lower than the thiol method, while the physicochemical properties of the wool keratin were similar to those obtained using reduction methods using thiol. The sulfitolysis method, adopting cheap and less harmful chemical agents, has a significant industrial impact on wool processing.

\subsection{2 lonic liquids}

Ionic liquids (ILs) with a low melting temperature have been widely used to dissolve various biomass due to their outstanding properties, including nonvolatility, nonflammability, thermal stability, easy recycling, and tunable structure [7]. Thus, a simple and eco-friendly method to extract wool keratin can be developed. Several research groups have attempted to fabricate wool keratin with different ILs. The extraction of wool keratin is generally based on a three-step process. The cleaned wool fibers are first added into the ILs with a magnetic stirrer, under nitrogen (N2) or air atmosphere. The dissolved wool keratin is then washed to remove any ionic liquid. Finally, keratin powders were obtained by ovendrying or freeze-drying.

Table 1 Characteristics of wool keratin dissolution conditions using the ILs method

\begin{tabular}{|c|c|c|c|}
\hline Agent & Dissolution conditions & Solubility (\%) & Ref. \\
\hline [BMIM]Br & $130^{\circ} \mathrm{C}, 10 \mathrm{~h}, \mathrm{~N}_{2}$ & 2.0 & [33] \\
\hline$\left[\mathrm{BMIM}_{\mathrm{B}} \mathrm{BF}_{4}\right.$ & $130^{\circ} \mathrm{C}, 24 \mathrm{~h}, \mathrm{~N}_{2}$ & Insoluble & [33] \\
\hline$\left[\mathrm{BMIM}_{\mathrm{P}} \mathrm{PF}_{6}\right.$ & $130^{\circ} \mathrm{C}, 24 \mathrm{~h}, \mathrm{~N}_{2}$ & Insoluble & [33] \\
\hline$[\mathrm{BMIM}] \mathrm{Cl}$ & $130^{\circ} \mathrm{C}, 10 \mathrm{~h}, \mathrm{~N}_{2}$ & 25.0 & {$[34]$} \\
\hline$[\mathrm{AMIM}] \mathrm{Cl}$ & $130^{\circ} \mathrm{C}, 10 \mathrm{~h}, \mathrm{~N}_{2}$ & 20.0 & {$[34]$} \\
\hline [AMIM] [dca] & $130^{\circ} \mathrm{C}, 10 \mathrm{~h}, \mathrm{~N}_{2}$ & 22.5 & {$[34]$} \\
\hline [choline] [thioglycolate] & $130^{\circ} \mathrm{C}, 10 \mathrm{~h}, \mathrm{~N}_{2}$ & 47.5 & {$[34]$} \\
\hline$[\mathrm{BPy}] \mathrm{Cl}$ & $130^{\circ} \mathrm{C}, 24 \mathrm{~h}$, air & Insoluble & {$[35]$} \\
\hline$\left[\mathrm{P}_{444}\right] \mathrm{Cl}$ & $130^{\circ} \mathrm{C}, 24 \mathrm{~h}$, air & Insoluble & {$[35]$} \\
\hline$\left[\mathrm{N}_{444}\right] \mathrm{Cl}$ & $130^{\circ} \mathrm{C}, 24 \mathrm{~h}$, air & Insoluble & {$[35]$} \\
\hline$\left[\mathrm{N}_{2221}\right] \mathrm{DMP}$ & $130^{\circ} \mathrm{C}, 3 \mathrm{~h}$, air & Dissolution & {$[35]$} \\
\hline [EMIM]DMP & $130^{\circ} \mathrm{C}, 1.5 \mathrm{~h}$, air & Dissolution & {$[35]$} \\
\hline$[\mathrm{BMIM}] \mathrm{OAC}$ & $130^{\circ} \mathrm{C}, 10 \mathrm{~min}$, air & Dissolution & {$[35]$} \\
\hline [BMIM]SCN & $130^{\circ} \mathrm{C}, 15 \mathrm{~h}$, air & Dissolution & {$[35]$} \\
\hline$[\mathrm{BMIM}] \mathrm{FeCl}_{4}$ & $130^{\circ} \mathrm{C}, 24 \mathrm{~h}$, air & Insoluble & {$[35]$} \\
\hline [BMIM]DMP & $130^{\circ} \mathrm{C}, 1.5 \mathrm{~h}$, air & Dissolution & {$[35]$} \\
\hline [EMIM]DMP & $130^{\circ} \mathrm{C}, 1.5 \mathrm{~h}$, air & Dissolution & {$[35]$} \\
\hline [DBNE]DEP & $120^{\circ} \mathrm{C}, 3 \mathrm{~h}$, air & Dissolution & {$[36]$} \\
\hline [DBNM]DMP & $120^{\circ} \mathrm{C}, 3.5 \mathrm{~h}$, air & Dissolution & {$[36]$} \\
\hline$[\mathrm{DBNH}] \mathrm{OAC}$ & $120^{\circ} \mathrm{C}, 0.33 \mathrm{~h}$, air & Dissolution & {$[36]$} \\
\hline [EMIM]OAC & $120^{\circ} \mathrm{C}, 0.5 \mathrm{~h}$, air & Dissolution & {$[37]$} \\
\hline [EMIM]Cl & $120^{\circ} \mathrm{C}, 0.5 \mathrm{~h}$, air & Dissolution & {$[37]$} \\
\hline [EMIM]DEP & $120^{\circ} \mathrm{C}, 0.5 \mathrm{~h}$, air & Dissolution & {$[37]$} \\
\hline$[\mathrm{HMIM}] \mathrm{Cl}$ & $120^{\circ} \mathrm{C}, 0.5 \mathrm{~h}$, air & Partial dissolution & {$[37]$} \\
\hline [BMIM]DBP & $120^{\circ} \mathrm{C}, 0.5 \mathrm{~h}$, air & Partial dissolution & {$[37]$} \\
\hline$[\mathrm{BMIM}] \mathrm{H}_{2} \mathrm{PO}_{4}$ & $120^{\circ} \mathrm{C}, 0.5 \mathrm{~h}$, air & No dissolution in $0.5 \mathrm{~h}$ & {$[37]$} \\
\hline
\end{tabular}


Xie et al. [33] compared the influence of [AMIM] Cl, [BMIM] $\mathrm{Cl},[\mathrm{BMIM}] \mathrm{Br},[\mathrm{BMIM}] \mathrm{BF}_{4}$, and $\left[\mathrm{BMIM}^{\mathrm{B}} \mathrm{PF}_{6}\right.$ on the solubility of wool fibers. The results showed that the $\mathrm{Cl}$ - ion showed better solubility for wool fibers than Br-, BF4-, and PF6-. The obtained wool keratin exhibited a $\beta$-sheet structure with no $\alpha$-helix structure. The regenerated keratin using ILs leads to a high thermal stability compared with natural wool. They also demonstrated that the [BMIM] $\mathrm{Cl}$ has the ability to significantly disrupt hydrogen bonds in wool keratin/cellulose blended materials.

Idris et al. [34] fabricated wool keratin with various ILs, including [BMIM] Cl, [AMIM] Cl, [AMIM][dca], and choline thioglycolate under an N2 atmosphere. The results in Table 1 provide evidence that [AMIM][dca] exhibited a high solubility of $47.5 \%$. Compared with other ILs, which are most commonly used in biopolymer extraction, the main advantage of [dca] is that it can disrupt the hydrogen-bonding in the protein aggregates. The authors added a reducing agent to the ILs to facilitate the dissolution of wool fibers. The results demonstrated that the reducing agent could increase the dissolution of the wool by $50-100 \mathrm{mg} / \mathrm{g}$. The authors attributed the improved solubility to the cleaving of the inter- and intra-molecular disulfide bonds caused by the reducing agent. The MWs of the regenerated keratin range from $15 \mathrm{kDa}$ to $>120 \mathrm{kDa}$, confirming that the ILs had cleaved the protein into smaller polypeptide chains.
The regenerated wool keratin with decreased crystallinity retained the protein backbone.

Zheng et al. [35] synthesized various ILs to investigate the influence of structures of cations and anions on dissolution capability for wool fiber. As listed in Table 1, the dissolution time is shortened to $10 \mathrm{~min}$ when using [EMIM]OAc. However, the structural and thermal stability of the regenerated wool keratin were damaged. Although [EMIM] DMP needed $1.5 \mathrm{~h}$ to dissolve the wool fibers, the proportion of $\alpha$-helical structure in the regenerated keratin was as high as $78.7 \%$. The wool keratin fabricated using [EMIM] DMP demonstrated high thermal stability and good reusability. This simple and effective method exhibited potential for the fabrication of wool keratin.

Liu et al. [36] synthesis a series of [DBNE] ILs with different anions to dissolve the wool fiber in an atmosphere of air. The regenerated keratin from the [DBNE] DEP ILs exhibited a crystallinity of $60.99 \%$ and an $\alpha$ helix of $57.88 \%$, which was higher than [DBNE] DEP and $[\mathrm{DBNH}] \mathrm{OAc}$. They proved that the [DBNE] DEP could be easily reused at least five times with stable structures and good dissolving ability.

While ILs satisfy the demands of good solubility for wool fiber, some of them could not guarantee the strength of regenerated keratin materials. Zhang et al. [37] studied the disulfide bonds and microstructure variation of regenerated wool keratin during the dissolution

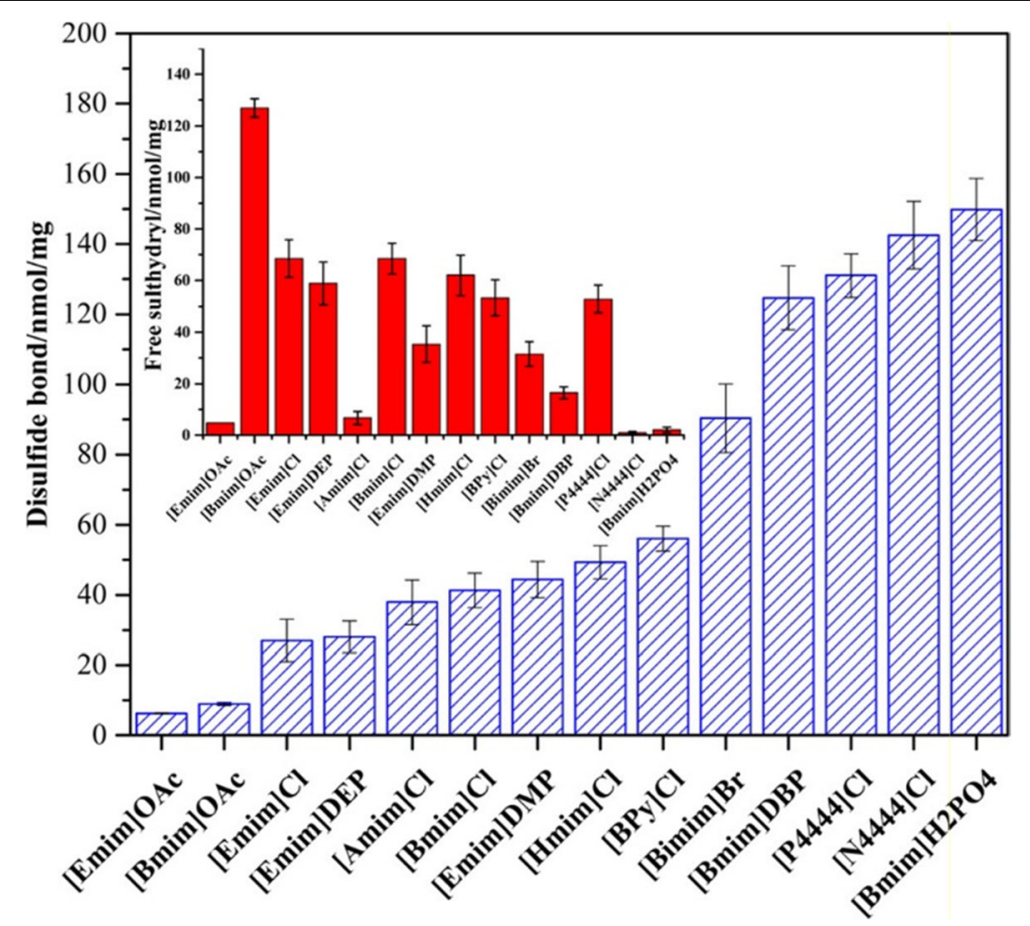

Fig. 4 Disulfide bonds and free sulfhydryl groups content of wool keratin regenerated from different ILs (120 $\left.{ }^{\circ} \mathrm{C}, 30 \mathrm{~min}\right)[37]$. Reprinted with permission from Reference [37]. Copyright 2017, American Chemical Society 
process for designing efficient ILs. As shown in Fig. 4, for the ILs incorporating [BMIM]+, the order of the ability to cleave the disulfide bonds followed [OAc]- > Cl- > $\mathrm{Br}->[\mathrm{DBP}]->[\mathrm{H} 2 \mathrm{PO} 4]-$. The disruption ability of -S$S$ - in keratin regenerated from $[\mathrm{EMIM}]+$ based ILs followed the order of [OAc] $->$ Cl- $>$ [DEP]- $>$ [DMP] Moreover, the imidazolium-based ILs showed a higher ability to cleave disulfide bonds than quaternary ammonium and phosphonium ILs. The authors claimed that the wool fibers are considered to be well dissolved when over $65 \%$ of the disulfide bonds are cleaved in the ILs. Meanwhile, optimal ILs with a disulfide bond cleaving ability of $70-80 \%$ can avoid the severe breakdown of keratin microstructure, making it suitable for fabricating keratin materials with good mechanical properties.

Generally, the extraction of wool keratin using ILs needs to be performed in an $\mathrm{N}_{2}$ atmosphere due to the hygroscopic nature of ILs, which needs expensive equipment. Another drawback is the limited reusability of ILs, increasing the cost of keratin extraction. According to the above discussion [35-37], properly designed of ILs have proved to be able to dissolve wool fibers efficiently with high protein yield under the atmosphere of air. The disruption of hydrogen and disulfide bonds is significantly related to the polarity of ILs. Therefore, the structure of anions and the cations should be considered in designing of ILs, rather than the slide chains of cations.

\subsubsection{Deep eutectic solvent and other methods}

Deep eutectic solvents (DES) have been used as alternative solvents for ILs in some cases owing to their similarities in physical properties with ILs, particularly their potential as tunable solvents that can be customized to a particular type of chemical reagent. Wang et al. [38] extracted wool keratin in the mixture of choline chloride/ oxalic acid (DES solvent). The optimized dissolution conditions were as follows: Choline chloride/oxalic acid molar ratio 1:2; wool-DES $5 \mathrm{wt} . \%, 110-125^{\circ} \mathrm{C}$, and $2 \mathrm{~h}$ reaction time. X-ray diffraction analysis highlighted that the wool fibers were decrystallized because of the use of the DES solvent. The as-prepared keratin had MWs ranging from $3.3-7.8 \mathrm{kDa}$, further confirming the good dissolution ability of DES solvents. Furthermore, the wool keratin fabricated using DES method has amino acid compositions similar to those of the wool fiber. Jiang et al. [39] replaced oxalic acid with urea as a co-solvent in the DES. They highlighted that the dissolution ability of wool fiber improved to $35.1 \mathrm{mg} / \mathrm{g}$ using DES at optimum conditions. The regenerated keratin in the MWs is in the range $43-67 \mathrm{kDa}$. The choline chloride/ urea mixed solvent was found to have a higher solubility of high-tyrosine and low-sulfur keratin that high-sulfur keratin. Most of the $\alpha$-helix crystal structure changed to a $\beta$-sheet or disordered structure during the extraction process.

Compared with traditional extraction methods, the advantages of the DES method are that the solvent is lowcost, biocompatible, and environmentally friendly, and specifically, the process has a low extraction temperature.

Lyu et al. [40] prepared size- and morphologycontrolled wool nanoparticles using the neutralization method and addressed the associated mechanisms for regulating the shape and size of wool nanoparticles. The well dispersed and stable wool nanoparticles with a size of $50 \mathrm{~nm}$ were obtained by the addition of $3 \%$ sodium hydroxide solution. XRD analysis demonstrated that the obtained wool nanoparticles maintained the chemical structure of the wool protein.

Wang et al. [41] extracted the wool keratin using Lcysteine as a reducing agent to dissolve the wool keratin better. The L-cysteine exhibited excellent solubility of $72 \%$, greater than other methods. The MWs of the obtained keratin were in the range $40-55 \mathrm{kDa}$. The results demonstrated that the regenerated keratin exhibited an increased $\beta$-sheet structure with a decreased $\alpha$-helix structure. An appropriate mechanism of the formation of wool keratin was proposed. The disulfide link was cleaved by either oxidization, or can, in part, form a new disulfide bridge.

He et al. [42] reported the use of ethanol as a cosolvent to weak the salt bond and hydrogen bond in wool fiber. The wool fiber dissolved in the L-cysteine hydrochloride, odium sulfite $\left(\mathrm{Na}_{2} \mathrm{SO}_{3}\right)$, and ethanol solution yields up to $67 \%$ keratin and is more efficient for extracting large molecular weight keratin $(130 \mathrm{kDa})$. This enhancement was attributed to the incorporation of ethanol, which facilitated the recombination of intermolecular - SH. This new avenue for the extraction of wool keratin is advantageous owing to its simplicity, stability, and high yield.

\section{Current applications of wool particles}

Wool particle, a kind of fibrous protein, which exhibits higher stability in comparison with most of the proteins. In this section, we focused on the applications of wool particles. At present, wool particles could be as textile materials, filtration adsorbents, cosmetic materials, and biomaterials, as shown in Fig. 5.

\subsection{Wool particle-based textiles}

Wool particles exhibit good capacity for moisture absorption, retention, and stability, and can be used as coating and modifying agents in textile processing.

Wool particle-based materials have received attention due to their ability to improve dyeing properties upon application as surface layers, fillers, or dyeing media for 


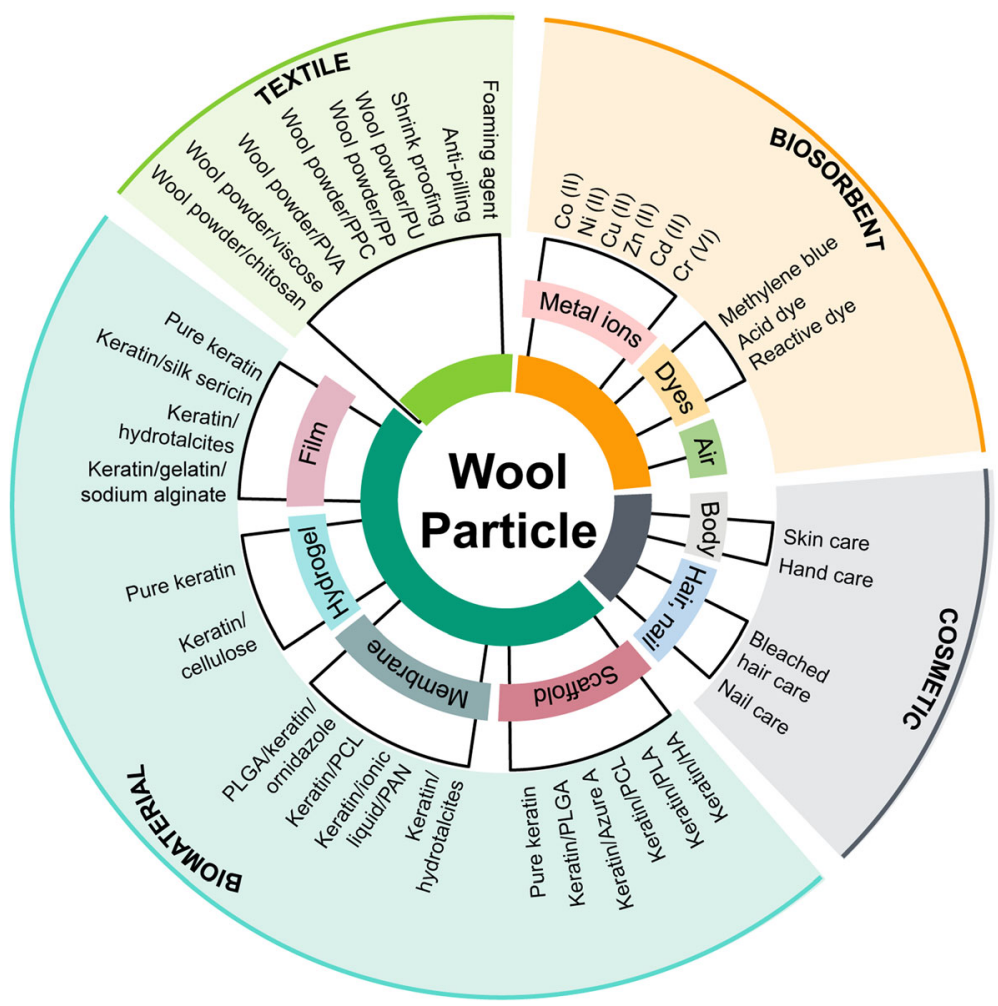

Fig. 5 Applications of wool particles

natural and synthetic polymers. Kantouch et al. [43] fabricated a keratin-coated wool fabric using epichlorohydrin as the cross-linking agent. They observed that the as-fabricated wool fabric exhibited enhanced dyeability with respect to acid and reactive dyes. Ke et al. [44] produced wool powder/chitosan composite membranes and reported that wool powders were necessary for an improvement in the water resistance and dyeing properties of chitosan. Incorporating wool powder into synthetic polymers could also improve the moisture absorption and dyeing properties of viscose and PP [45-47]. In addition, wool keratin hydrolysates were for the first time used as a foaming agent in the dyeing of wool and cotton fabrics [48]. The role of hydrolyzed keratin is to convey the dye molecules during the dyeing process as illustrated in Fig. 6. Results showed that the foam-dyed cotton fabric yielded a K/S value that was similar to those observed for conventional padding samples. The foam-dyed wool fabric yields a higher $\mathrm{K} / \mathrm{S}$ value as compared to that of the traditional pad steam. The utilization of hydrolyzed keratin as a foaming agent is a promising method of dyeing due to its favorable qualities

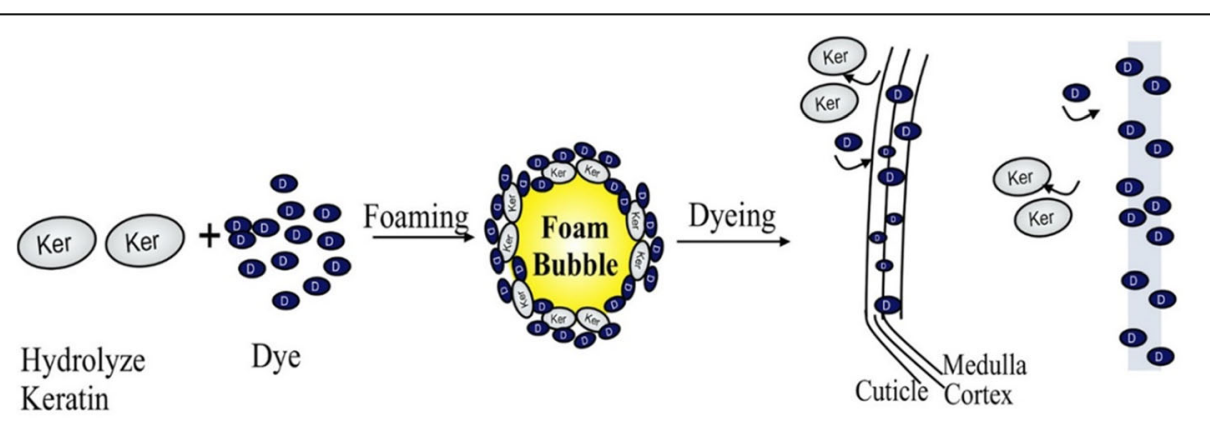

Acid dyeing Reactive dyeing of wool of cotton

Fig. 6 Hypothetical mechanism for foam dyeing of cotton and wool fabric using keratin hydrolysate [48]. Reprinted with permission from Reference [48]. Copyright 2017, American Chemical Society 
of low-cost, good foam stability, energy-saving capacity, and environment friendliness.

Wool particles are commonly considered by researchers as fillers for the attainment of composites with good moisture permeability. Wool powder/PU composite film was clearly found to significantly improve water vapor permeability and moisture regain [49]. In addition, wool powder could improve the ability to absorb moisture and formaldehyde of PVA composites [24].

Wool particles are also used as reinforcing fillers in the obtainment of composites with high mechanical properties. The $2 \mathrm{wt} \%$ wool powder/PPC composites obtained through solvent evaporation and hot-compression indicated an improvement in the mechanical properties, glass transition performance, and thermal decomposition temperatures [50].

The use of surface treatment to improve the antifelting of wool has received particular attention. Keratin has been deposited as a coating on wool fabric through a combination of L-cysteine pretreatment and wool keratin cross-link fixation [51]. The anti-felting finishing process is illustrated in Fig. 7. The authors demonstrated that wool fabric possessed good anti-felting capacity by using keratin recycled for the tenth time. The surface of the processed wool fabric was found to be similar to that of the original wool fabric. Moreover, the wool keratintreated wool fabric has the advantages of improved hydrophilicity, whiteness, softness, and dyeability, as compared to those of the untreated wool fabric. The main advantage of this method is the environmentfriendliness of keratin and its capacity to be reused as the finishing agent at least 10 times. Jia et al. [52] developed a novel anti-shrink finishing agent using keratin. The anti-pilling grade of keratin-treated wool fabric reaches up to 4.5 .

Wool keratin hydrolysate can be used to improve exhaustion in the leather tanning process. Keratin has the ability to react with chromium and further enhance the uptake of chromium by leather. In addition, keratin can be used with retanning agents to improve the grain smoothness and softness of leathers [5]. All these studies suggest that keratin-based materials exhibit a wide range of applicability as a functional finishing agent.

\subsection{Wool particle-based biosorbent}

Regenerated wool particles have been demonstrated as suitable potential sorbents due to their high surface activity, large surface area, and low density. Wool particlebased materials are commonly used to adsorb dye effluents, heavy metals, and toxic gases.

Dyes are an essential requirement in various significant industries such as tannery, paper, and textile industries because of their color-giving properties. Due to its low-cost and eco-friendliness, physical adsorption is one of the most important methods of removing dyes from wastewater. To address the issue of dye, Wen et al. [53] fabricated wool powder with a particle diameter of $4.5 \mu \mathrm{m}$ for the purpose of absorbing acid dyes and methylene blue. The methylene blue sorption capacity of wool powder was $142.9 \mathrm{mg} / \mathrm{g}$, while that of the activated charcoal was $0.024 \mathrm{mg} / \mathrm{g}$; these results indicated good dye absorption. Due to the electrostatic force between acid dyes and wool powders, the C.I. acid red 88 sorption capacity of wool powder was $555.6 \mathrm{mg} / \mathrm{g}$. Wool

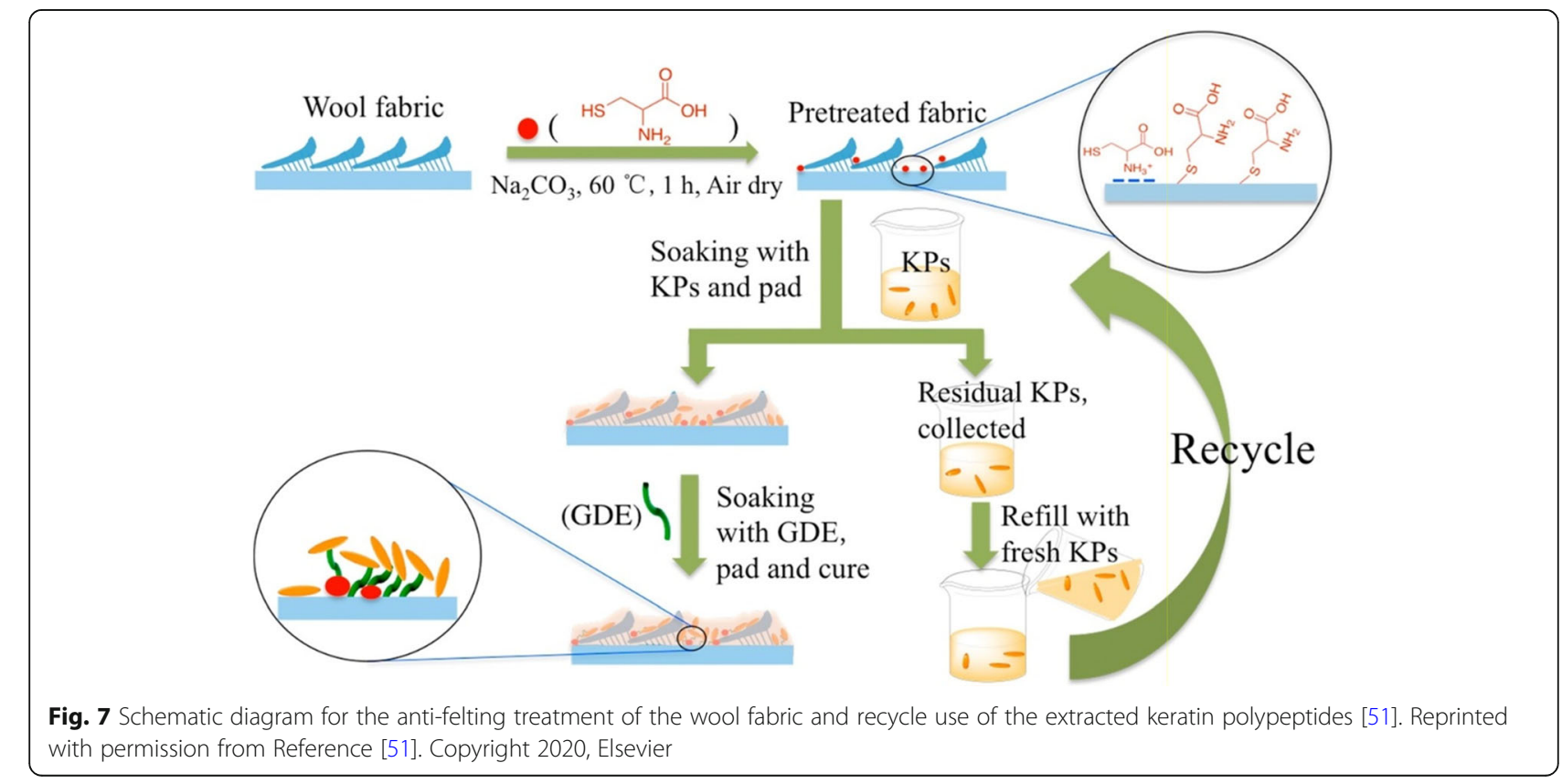


powder exhibited the capacity to be a good dye sorbent with excellent acid dye absorption capacity at room temperature. Furthermore, Glafar et al. [54] demonstrated that the use of wool powders modified with citric acid monohydrate improved the efficiency of methylene blue removal from 75 to $86 \%$. On the other hand, Aluigi et al. [55]. fabricated highly porous keratin nanofibrous through electrospinning. Free-standing and flexible keratin membranes demonstrated good adsorption of methylene blue. The authors proposed the potential application of keratin nanofibrous membranes as dye adsorption filters.

The presence of heavy metal ions in wastewater is another serious problem that could cause biological hazards. The metal iron adsorption of wool proteins was closely related to their morphology. The most crucial aspect of an adsorbent is its adsorption capacity. The metal-ion adsorption capacities of various keratin-based materials were compared in Table 2. EI-sayed et al. [56] reported that wool powder exhibited significantly higher $\mathrm{Cu}$ (II) and $\mathrm{Zn}$ (II) adsorption capacities than that of wool fiber (approximately three-fold). Wool powders demonstrated a relatively better ability to remove $\mathrm{Cu}$ (II), which was attributed to the strong interaction between $\mathrm{Cu}$ (II) and wool. The author found that wool powder could sustain its ability to absorb $\mathrm{Cu}$ (II) and $\mathrm{Zn}$ (II) after four cycles of absorption/desorption. Naik et al. [57] also found that the $\mathrm{Cu}$ (II) uptake rate of the wool powder was significantly higher than that of the wool fiber (approximately 42-fold). They demonstrated that after pretreatment with $4 \%$ sodium salt, wool powder (approximately $4.6 \mu \mathrm{m}$ ) exhibited a seven-fold increase in Co (II) adsorption as compared to that observed for the wool snippets (approximately $500 \mu \mathrm{m}$ ), because the Co (II) exhibited a weak binding affinity for wool fiber. Among keratin-based materials, keratin solution displayed the lowest percentage of ion removal [58]. Compared with the keratin nanofiber membrane fabricated by Aluigi et al. [59, 61, 62] the keratin/polymer composite showed enhanced adsorption of metal irons. Aluigi et al. revealed that keratin/PVA nanofibers exhibited a high capacity to adsorb $\mathrm{Cu}$ (II). The adsorption capacity of keratin/PVA nanofibers increased when the surface area of the nanofiber mats was increased. Jin et al. [63] proposed that the adsorption removal of $\mathrm{Cr}(\mathrm{VI})$ was mainly a result of the electrostatic adsorption of the amino acids and the redox reaction of disulfide bond in cystine oxide. The development of the wool keratin/PET composite may have significant potential for application in $\mathrm{Cr}(\mathrm{VI})$ removal.

Li et al. [64] developed an eco-friendly air purification filter using keratin/PEO nanofibers. The filtration efficiency of keratin/PEO-based nonwoven polypropylene (PP) fabric reached up to $88 \%$, which is higher than that of the two-layer nonwoven PP fabric (only 2.5\%). In addition, Shen et al. [65] found that the keratin/polyamide- 6 composite nanofiber membrane improved air filtration efficiency and water-vapor transmission. These research studies revealed that wool keratin could be a promising material for the fabrication of novel filter materials.

Table 2 Metal ions adsorption performances of various wool particle-based materials

\begin{tabular}{|c|c|c|c|c|}
\hline Sample & lons & Adsorption capacity (mg/g) & Initial ions concentration (mg/L) & Ref. \\
\hline Wool powder & $\mathrm{Cu}(\mathrm{II})$ & 122.1 & 100 & {$[56]$} \\
\hline Wool powder & $\mathrm{Zn}(I I)$ & 73 & 100 & {$[56]$} \\
\hline Wool powder & Co (II) & - & - & {$[57]$} \\
\hline Wool powder & $\mathrm{Cu}(\mathrm{II})$ & - & - & {$[57]$} \\
\hline Wool powder & $\mathrm{Cd}(\mathrm{II})$ & - & - & {$[57]$} \\
\hline Keratin solution & $\mathrm{Cd}(\mathrm{II})$ & 0.73 & 16.86 & {$[58]$} \\
\hline Keratin solution & $\mathrm{Cu}(\mathrm{II})$ & 0.55 & 9.52 & [58] \\
\hline Keratin solution & $\mathrm{Ni}(I I)$ & 0.48 & 8.8 & [58] \\
\hline Keratin solution & $\mathrm{Zn}(I I)$ & 0.46 & 9.81 & [58] \\
\hline Keratin nanofibers & $\mathrm{Cu}(\mathrm{II})$ & 30 & 20 & [59] \\
\hline Keratin nanoparticles & $\mathrm{Cu}(\mathrm{II})$ & 50 & 100 & {$[60]$} \\
\hline Keratin nanofiber membrane & $\mathrm{Cu}(\mathrm{II})$ & 11.03 & 50 & {$[61]$} \\
\hline Keratin nanofiber membrane & $\mathrm{Cu}(\mathrm{II})$ & 4 & 5.82 & {$[61]$} \\
\hline Keratin/PA6 (90/10) blend nanofibers & $\mathrm{Cu}(\mathrm{II})$ & 103.5 & 35 & [62] \\
\hline Keratin/PA6 (70/30) blend nanofibers & $\mathrm{Cu}(\mathrm{II})$ & 90 & 35 & {$[62]$} \\
\hline Keratin/PA6 (50/50) blend nanofibers & $\mathrm{Cu}(\mathrm{II})$ & 61.7 & 35 & [62] \\
\hline Keratin/PET nanofiber membrane & $\mathrm{Cr}(\mathrm{VI})$ & 75.86 & 100 & {$[63]$} \\
\hline
\end{tabular}




\subsection{Wool particle-based cosmetic materials}

Wool keratin-based cosmetics have been reported to be used as hair and skin care products due to their numerous merits including smoothness, luster, softness, elasticity, and protective efficacy. Barba et al. [66] found that wool keratin could improve the moisture absorption and desorption capacity of bleached hair. In addition, they evaluated the water barrier function of the skin after the use of wool keratin peptides [67]. The results showed that the skin exhibited an improved water holding capacity and elasticity after the use of wool keratin peptides. Bayramoglu et al. [68] stated that keratin/Calendula extract emulsions could be entirely absorbed by the skin and did not leave any waste on the skin surface. As mentioned above, wool keratin was demonstrated as being versatile for the fabrication of cosmetic materials.

\subsection{Wool particle-based biomaterials}

The wool keratin-based composites integrate the physicochemical and biological properties of both materials, rendering them ideal for tissue engineering, wound dressings, biomedical applications, drug-delivery systems, bio-inks, and bioplastics, as shown in Fig. 8.

The structure of wool keratin is similar to that of collagen, rendering it a possible choice for tissue repair applications. As the first line of defense, skin is prone to damage in fire and traffic accidents and has limited selfhealing ability. A moist environment around the wound, good ventilation to stimulate cell growth, and low bacterial load are conducive to proper wound recovery. It is common knowledge that open wounds promote microbial growth. To address this issue, Aluigi et al. [69] first fabricated wool keratin doped with a methylene blue film using a solvent casting method. Up to $99.9 \%$ of Staphylococcus aureus (S. aureus) with concentration of $108 \mathrm{cfu} / \mathrm{mL}$ were successfully annihilated using the wool keratin-based film under visible light. In yet another endeavor to prevent microbial growth, keratin/ionic liquid/PAN nanofibrous membranes exhibited a good water transport capacity and an effective antibacterial activity against Escherichia coli (E. coli) and S.aureus [70]. The proliferation of cells in the wound area could promote the rapid repair of injured skin. Introduction of gelatin and sodium alginate into keratin via the casting method resulted in a composite film with good thermal, mechanical, cell proliferation, swelling, and antibacterial properties, thereby promoting faster cell growth in the wound area [74]. In addition, keratin-based materials were found to support hBMMSCs, mouse fibroblast, $\mathrm{PC}_{2}, \mathrm{HOS}, \mathrm{MEFs}$, and adult mammalian skin cells [71, 72, 75-77]. Moreover, wool keratin was found to be a possible choice for application in drug release and delivery systems for personalized wound or tissue repair. The ornidazole has strong inhibitory and deadly effects against most anaerobes. In particular, 1\% ornidazole/PLGA/keratin membrane exhibited drug release characteristics and biodegradability in vitro, and could promote the growth and proliferation of hPDLFs, resulting in the treatment of periodontal disease and repair of periodontal defects [78]. Giuri et al. [79] used non-woven keratin/hydrotalcites to fabricate drug delivery systems and scaffolds for fibroblast cell growth. The non-woven keratin/hydrotalcites exhibited good biocompatibility and a controlled diclofenac release, thereby facilitating the growth of fibroblast cells.

The thermoplasticity and biocompatibility of keratin is conducive to its production of tissue-like structures that are used in bio-ink printing; these properties are expected to facilitate tissue construction and host tissue integration, such as vascularization and cell infiltration [28]. This provides a novel method of printing and weaving tissue structures using biomaterials. Furthermore, wool particles have also been used in the preparation of environment-friendly bioplastics. Wang et al. [80] fabricated a hot-pressed wool powder film mixed with plasticizer glycerol. The as-prepared wool film was ductile and soft, which can be used as a bioplastic for packaging applications. Arlas et al. [73] used glycerin and SDS to plasticize the keratin film. The resulting bioplastic exhibited a good transparency, a large UV barrier capacity, an excellent thermal stability, and decent mechanical properties. It was also potentially applicable in regenerative medicine, coatings, and packaging.

\section{Conclusions and outlooks}

In this study, we present a comprehensive review of the utilization of wool waste. We focused on the mechanical and chemical recycle methods along with associated formation mechanisms, their structure, properties, and promising applications. Despite that the remarkable developments of wool particle and wool particle-based composites have been reviewed in this paper, some issues and challenges are also needed to be addressed in large-scale production.

As a rapid, simple, and high-efficiency approach to wool powder production, the mechanical method can maintain the structure of the protein. More importantly, the yield from the mechanical method is high; some can even reach $100 \%$. The pretreatment, temperature, pressure, and milling time are essential to control the shape and size of the wool powders. As discussed above, pretreatment of wool fibers with steam or chemical reagents can further reduce the particle size of wool powders. However, the production of nanowool powder with regular shape, particularly spherical particles using the mechanical method, is challenging. At present, the main goal is to combine milling methods with other pretreatments to eliminate their limitations and disadvantages. Additionally, the interfacial interaction between wool 


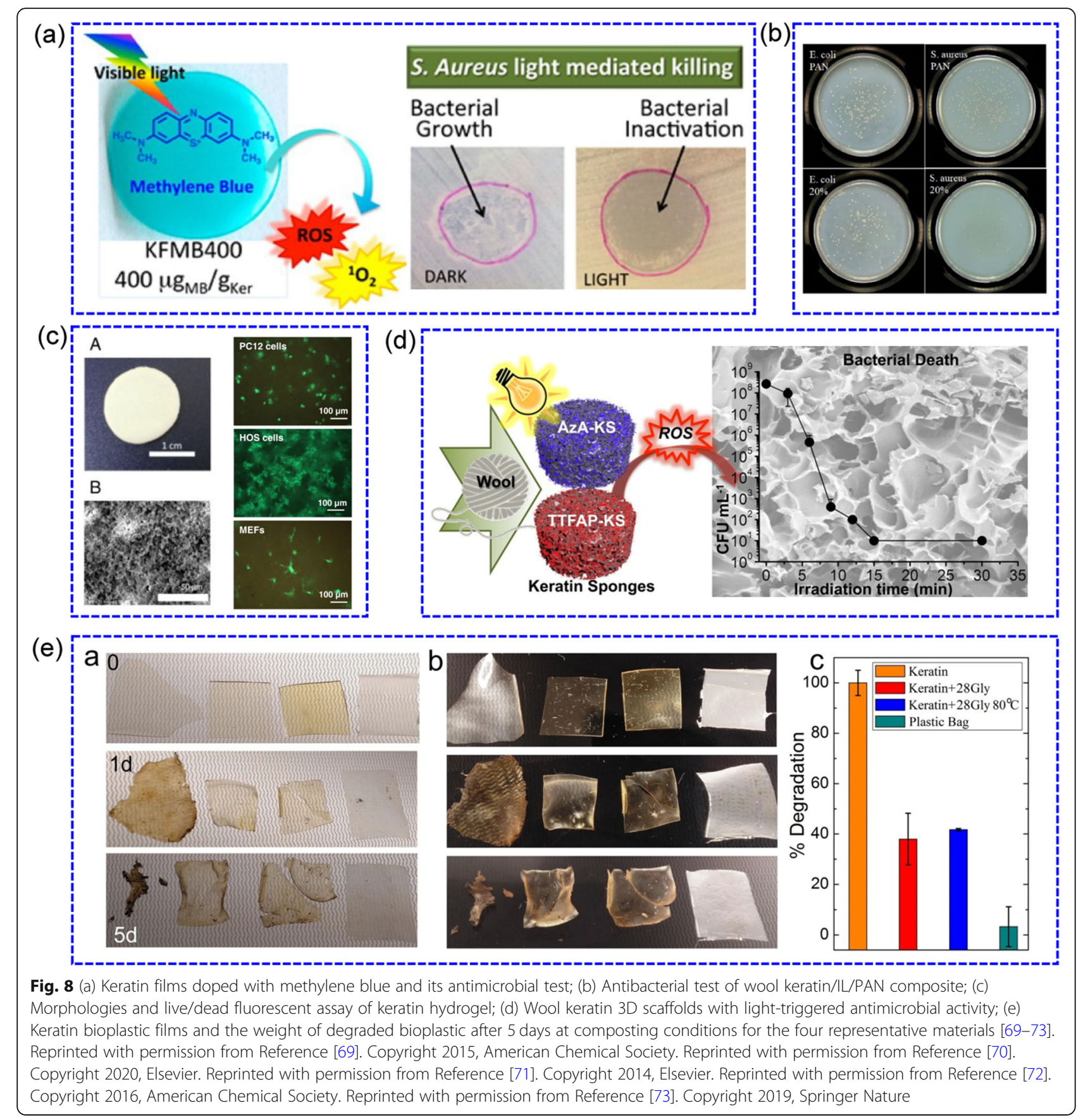

powder and polymer matrix need to be improved to enhance the mechanical property of wool powder-based composites.

Wool keratin is a kind of fibrous protein to be exploited for the design of advanced biomaterials, due to its physical properties, biocompatibility, and biodegradability. A critical challenge with wool keratin is the reliable and environmentally friendly extraction method. Another challenge is that the MWs and yield of wool keratin can be controlled in mass production to obtain wool particle-based composites with high mechanical properties.

\section{Abbreviations}

ILs: Ionic liquids; DES: Deep eutectic solvent; MWs: Molecular weights; [BMIM]Br: 1-butyl-3-methylimidazolium bromide; [BMIM]BF4: 1-butyl-3methylimidazolium tetrafluoroborate; [BMIM]PF6: 1-butyl-3methylimidazolium hexafluorophosphate; [BMIM]Cl: 1-butyl-3methylimidazolium chloride; [AMIM]Cl: 1-allyl-3-methylimidazolium chloride; [AMIM] [dca]: 1-allyl-3-methylimidazolium dicyanamide; [BPy]Cl: 1- 
butylpyridinium chloride; [P4444]Cl: Tetrabutylphosphonium chloride; $\left[\mathrm{N}_{444}\right] \mathrm{Cl}$ : Tetrabutylammonium chloride;

[N222] ]DMP: Triethylmethylammonium dimethylphosphate; [EMIM]DMP: 1ethyl-3-methylimidazolium dimethylphosphate; [BMIM]OAc: 1-butyl-3methylimidazolium acetate; [BMIM]SCN: 1-butyl-3-methylimidazolium thiocyanogen; [BMIM] $\mathrm{FeCl}_{4}$ : 1-butyl-3-methylimidazolium tetrachloroferrate; [BMIM]DMP: 1-butyl-3-methylimidazolium dimethyl phosphate; [DBNE]DEP: 1ethyl-1,5-diazabicyclo [4.3.0]-non-5-enium diethylphosphate; [DBNM]DMP: 1methyl-1,5-diazabicyclo [4.3.0]-5-enium dimethyl phosphate; [DBNH]OAc: 1,5diazabicyclo [4.3.0] non-5-enium acetate; [EMIM]OAc: 1-ethyl-3methylimidazolium acetate; [EMIM]Cl: 1-ethyl-3-methylimidazolium chloride; [EMIM]DEP: 1-ethyl-3-methylimidazolium diethylphosphate; [HMIM]Cl: 1methylimidazolium chloride; [BMIM]DBP: 1-butyl-3-methylimidazolium dibutylphosphate; [BMIM] $\mathrm{H}_{2} \mathrm{PO}_{4}$ : 1-butyl-3-methylimidazolium dihydrogen phosphate; PP: Polypropylene; PPC: Poly (propylene carbonate): PVA: Polyvinyl alcohol; PA: Polyamide; PET: Polyethylene terephthalate; PEO: Polyethylene oxide; PLLA: Poly (L-lactic) acid; hBM-MSCs: Human bone marrow mesenchymal stem cells; $\mathrm{PC1}_{2}$ : Pheochromocytoma; HOS: Human osteosarcoma; MEFs: Primary culture of murine embryonic fibroblasts; hPDLFs: Human periodontal ligament fibroblasts; PCL: Polycaprolactone; PLGA: Poly (lactic-co-glycolic acid); PAN: Polyacrylonitrile; SDS: Sodium dodecyl sulfate; PLA: Polylactide acid; HA: Hydroxyapatite

\section{Acknowledgments}

This work was supported by the National Natural Science Foundation of China (Grant 21905214); National Natural Science Foundation of China (Grant 51773158); Excellent Young Science and Technology Innovation Team of Hubei High School (Grant T201707); and opening project of State Key Laboratory of Silkworm Genome Biology, Ministry of Agriculture, Southwest University for their financial support.

\section{Authors' contributions}

CZ: Writing this review article, summarizing the literatures; LX: Designing Figs. 3 and 5, and revising the draft; JZ: Collecting references and designing Fig. 1; XL: Revising the draft, mainly focus on the language and logicality; WX: Designing the outline of the draft and revising the draft. All authors read and approved the final manuscript.

\section{Funding}

National Natural Science Foundation of China (Grant 21905214); National Natural Science Foundation of China (Grant 51773158); Excellent Young Science and Technology Innovation Team of Hubei High School (Grant T201707).

\section{Availability of data and materials}

Not applicable.

\section{Competing interests}

The authors declare that have no competing interests.

\section{Author details}

${ }^{1}$ State Key Laboratory of New Textile Materials and Advanced Processing Technologies, Wuhan Textile University, Wuhan 430200, China. ${ }^{2}$ College of Material Science and Engineering, Wuhan Textile University, Wuhan 430200, China. ${ }^{3}$ State Key Laboratory of Silkworm Genome Biology, Ministry of Agriculture, Southwest University, Chongqing 400715, China. ${ }^{4}$ Institute for Frontier Materials, Deakin University, Geelong, Victoria 3216, Australia.

\section{Received: 1 April 2020 Accepted: 21 June 2020}

\section{Published online: 03 July 2020}

\section{References}

1. Rouse JG, Van Dyke ME. A review of keratin-based biomaterials for biomedical applications. Materials. 2010;3(2):999-1014.

2. Barone JR, Schmidt WF, Liebner CFE. Thermally processed keratin films. J Appl Polym Sci. 2005;97(4):1644-51.

3. Patil K, Rajkhowa R, Wang X, Lin T. Review on fabrication and applications of ultrafine particles from animal protein fibres. Fiber Polym. 2014;15(2):187-94.

4. Donato RK, Mija A. Keratin associations with synthetic, biosynthetic and natural polymers: an extensive review. Polymers (Basel). 2019;12(1):32.
5. Karthikeyan R, Balaji S, Sehgal PK. Industrial applications of keratins-a review. J Sci Ind Res. 2007;66:710-5.

6. Ghosh A, Collie S. Keratinous materials as novel absorbent systems for toxic pollutants. Def Sci J. 2014;64(3):209-21.

7. Shavandi A, Silva TH, Bekhit AA, Bekhit AEA. Keratin: dissolution, extraction and biomedical application. Biomater Sci. 2017;5(9):1699-735.

8. Shavandi A, Ali MA. Graft polymerization onto wool fibre for improved functionality. Prog Org Coat. 2019;130:182-99.

9. Shavandi A, Ali MA. Keratin based thermoplastic biocomposites: a review. Rev Environ Sci Biotechnol. 2019;18(2):299-316.

10. Idris A, Vijayaraghavan R, Rana UA, Fredericks D, Patti AF, MacFarlane DR. Dissolution of feather keratin in ionic liquids. Green Chem. 2013;15(2):525.

11. Xu W, Cui W, Li W, Guo W. Development and characterizations of super-fine wool powder. Powder Technol. 2004;140(1-2):136-40.

12. Xu W, Guo W, Li W. Thermal analysis of ultrafine wool powder. J Appl Polym Sci. 2003;87:2372-6.

13. Li Y, Xu WL, inventors. Apparatus for producing fine powder: United States Patent 7,000,858. Washington, DC. U.S. 2006.

14. Xiao SL, Wang ZJ, Ma H, Yang HJ, Xu WL. Effective removal of dyes from aqueous solution using ultrafine silk fibroin powder. Adv Powder Technol. 2014;25(2):574-81.

15. Xu WL, Wang X, Cui WG, Peng XQ, Li WB, Liu X. Characterization of superfine down powder. J Appl Polym Sci. 2009;111(5):2204-9.

16. Xia L, Li C, Zhou S, Fu Z, Wang Y, Lyu P, Zhang J, Liu X, Zhang C, Xu W. Utilization of waste leather powders for highly effective removal of dyes from water. Polymers (Basel). 2019;11(11):1786.

17. Gan L, Guo H, Xiao Z, Jia Z, Yang H, Sheng D, Pan H, Xu W, Wang Y. Dyeing and characterization of cellulose powder developed from waste cotton. Polymers (Basel). 2019;11(12):1982.

18. Rajkhowa R, Zhou Q, Tsuzuki T, Morton DAV, Wang X. Ultrafine wool powders and their bulk properties. Powder Technol. 2012;224:183-8.

19. Wen G, Rippon JA, Brady PR, Wang XG, Liu X, Cookson PG. The characterization and chemical reactivity of powdered wool. Powder Technol. 2009;193(2):200-7.

20. Al Faruque MA, Remadevi R, Wang XG, Naebe M. Preparation and characterisation of mechanically milled particles from waste alpaca fibres. Powder Technol. 2019;342:848-55.

21. Patil K, Rajkhowa R, Dai XJ, Tsuzuki T, Lin T, Wang XG. Preparation and surface properties of cashmere guard hair powders. Powder Technol. 2012;219:179-85.

22. Tonin C, Zoccola M, Aluigi A, Varesano A, Montarsolo A, Vineis C, Zimbardi F. Study on the conversion of wool keratin by steam explosion. Biomacromolecules. 2006;7:3499-504.

23. Hassabo AG, Salama M, Mohamed AL, Popescu C. Ultrafine wool and cotton powder and their characteristics. J Nat Fiber. 2014;12(2):141-53.

24. Hassabo AG, Salama M, Popescu C. Charcterizations of PVA comoposites based on recycled ultrafine cotton and wool powders. Res Rev Biosci. 2015; 10(4):147-58.

25. Cheng YF, Yuen CWM, Li Y, Ku SKA, Kan CW, Hu JY. Characterization of nanoscale wool particles. J Appl Polym Sci. 2007;104(2):803-8.

26. Pakkaner E, Yalcin D, Uysal B, Top A. Self-assembly behavior of the keratose proteins extracted from oxidized Ovis aries wool fibers. Int I Biol Macromol. 2019;125:1008-15.

27. Buchanan JH. A cystine-rich protein fraction from oxidized a-keratin. Biochem J. 1977;167(2):489-91.

28. Richards DJ, Tan Y, Jia J, Yao H, Mei Y. 3D printing for tissue engineering. Isr J Chem. 2013;53(9-10):805-14.

29. Yamanaka T, Iwashita S, Takigami S. Preparation and application of soluble wool keratin. Trans Mater Res Soc Japan. 2010;35(2):347-50.

30. Fitz-Binder C, Pham T, Bechtold T. A second life for low-grade wool through formation of all-keratin composites in cystine reducing calcium chloridewater-ethanol solution. J Chem Technol Biotechnol. 2019;94(10):3384-92.

31. Yamauchi K, Yamauchi A, Kusunoki T, Kohda A, Konishi Y. Preparation of stable aqueous solution of keratins, and physiochemical and biodegradational properties of films. J Biomed Mater Res. 1996;31:439-44.

32. Shavandi A, Bekhit AEA, Carne A, Bekhit A. Evaluation of keratin extraction from wool by chemical methods for bio-polymer application. J Bioact Compat Pol. 2017;32(2):163-77.

33. Xie HB, Li SH, Zhang SB. Ionic liquids as novel solvents for the dissolution and blending of wool keratin fibers. Green Chem. 2005;7(8):606.

34. Idris A, Vijayaraghavan R, Rana UA, Patti AF, MacFarlane DR. Dissolution and regeneration of wool keratin in ionic liquids. Green Chem. 2014;16(5):2857-64. 
35. Zheng SS, Nie Y, Zhang SJ, Zhang XP, Wang LJ. Highly efficient dissolution of wool keratin by dimethylphosphate ionic liquids. ACS Sustain Chem Eng. 2015;3(11):2925-32.

36. Liu X, Nie Y, Meng XL, Zhang ZL, Zhang XP, Zhang SJ. DBN-based ionic liquids with high capability for the dissolution of wool keratin. RSC Adv. 2017;7(4):1981-8.

37. Zhang ZL, Nie Y, Zhang QS, Liu X, Tu WH, Zhang XP, Zhang SJ. Quantitative change in disulfide bonds and microstructure variation of regenerated wool keratin from various ionic liquids. ACS Sustain Chem Eng. 2017;5(3):2614-22.

38. Wang D, Tang R-C. Dissolution of wool in the choline chloride/oxalic acid deep eutectic solvent. Mater Lett. 2018;231:217-20.

39. Jiang Z, Yuan J, Wang P, Fan X, Xu J, Wang Q, Zhang L. Dissolution and regeneration of wool keratin in the deep eutectic solvent of choline chloride-urea. Int J Biol Macromol. 2018;119:423-30.

40. Lyu P, Zhang C, Wang Y, Li C, Xiang X, Zhou J, Xu W, Liu X. A simple way of fabricating lyophilized wool nanoparticle powders using neutralization method. Adv Powder Technol. 2020;31(1):87-93.

41. Wang K, Li R, Ma JH, Jian YK, Che JN. Extracting keratin from wool by using I-cysteine. Green Chem. 2016;18(2):476-81.

42. He J, Xu D, Li J, Li L, Li W, Cui W, Liu K. Highly efficient extraction of large molecular-weight keratin from wool in a water/ethanol co-solvent. Text Res J. 2019;90(9-10):1084-93.

43. Kantouch A, Allam O, El-Gabry L, El-Sayed H. Effect of pretreatment of wool fabric with keratin on its dyeability with acid and reactive dyes. Indian J Fibre Text Res. 2012;37:157-61.

44. Ke G, Xu W. Preparation and properties of superfine wool powder/chitosan complex membrane. J Text Inst. 2012;103(11):1183-8.

45. Li W, Ke G, Li G, Xu W. Study on the structure and properties of viscose/ wool powder blended fibre. Fibers Text East Eur. 2015;1(109):26-9.

46. Xu W, Wang X, Li W, Peng X, Liu X, Wang XG. Characterization of superfine wool powder/poly (propylene) blend film. Macromol Mater Eng. 2007; 292(5):674-80

47. Wang $X, X u$ W, Cui W, Li W, Wang X. Bleaching and dyeing of superfine wool powder/polypropylene blend film. Res J Text Appar. 2008;12(4):12-20.

48. Bhavsar PS, Zoccola M, Patrucco A, Montarsolo A, Mossotti R, Giansetti M, Rovero G, Maier SS, Muresan A, Tonin C. Superheated water hydrolyzed keratin: a new application as a foaming agent in foam dyeing of cotton and wool fabrics. ACS Sustain Chem Eng. 2017:5(10):9150-9.

49. Xu W, Fang J, Cui W, Huang J. Modification of polyurethane by superfine protein powder. Polym Eng Sci. 2006;46(5):617-22.

50. Chang H, Li Q, Xu C, Li R, Wang H, Bu Z, Lin T. Wool powder: an efficient additive to improve mechanical and thermal properties of poly (propylene carbonate). Compos Sci Technol. 2017;153:119-27.

51. Du Z, Ji B, Yan K. Recycling keratin polypeptides for anti-felting treatment of wool based on L-cysteine pretreatment. J Clean Prod. 2018;183:810-7.

52. Jia JR, Yao JB, Liu JY, Liu YB. Application of dissolved wool keratin in antipilling processing. Key Eng Mater. 2015;671:53-8.

53. Wen G, Cookson PG, Liu X, Wang XG. The effect of $\mathrm{pH}$ and temperature on the dye sorption of wool powders. J Appl Polym Sci. 2010;116:2216-26.

54. Ghafar HHA, Salem T, Radwan EK, El-Sayed AA, Embaby MA, Salama M. Modification of waste wool fiber as low cost adsorbent for the removal of methylene blue from aqueous solution. Egypt J Chem. 2017;0(0):0.

55. Aluigi A, Rombaldoni F, Tonetti C, Jannoke L. Study of methylene blue adsorption on keratin nanofibrous membranes. J Hazard Mater. 2014;268: 156-65.

56. Atef El-Sayed A, Salama M, Kantouch AAM. Wool micro powder as a metal ion exchanger for the removal of copper and zinc. Desalin Water Treat. 2014;56(4):1010-9.

57. Naik R, Wen G, Ms D, Hureau S, Uedono A, Wang X, Liu X, Cookson PG, Smith SV. Metal ion binding properties of novel wool powders. J Appl Polym Sci. 2010;115(3):1642-50

58. Nikiforova $T$, Kozlov $V$, Islyaikin M. Sorption of $d$-metal cations by keratin from aqueous solutions. J Environ Chem Eng. 2019;7(5):103417.

59. Aluigi. Wool keratin nanofibres for copper (II) adsorption. J Biobased Mater Bioenergy. 2012;6(2):230-6.

60. Mousavi SZ, Manteghian M, Shojaosadati SA, Pahlavanzadeh H. Keratin nanoparticles: synthesis and application for Cu (II) removal. Adv Environ Technol. 2018;2:83-93.

61. Aluigi A, Corbellini A, Rombaldoni F, Mazzuchetti G. Wool-derived keratin nanofiber membranes for dynamic adsorption of heavy-metal ions from aqueous solutions. Text Res J. 2012;83(15):1574-86.
62. Aluigi A, Tonetti C, Vineis C, Tonin C, Mazzuchetti G. Adsorption of copper (II) ions by keratin/PA6 blend nanofibres. Eur Polym J. 2011;47(9):1756-64.

63. Jin $X$, Wang $H$, Jin X, Wang $H$, Chen L, Wang W, Lin T, Zhu Z. Preparation of keratin/PET nanofiber membrane and its high adsorption performance of $\mathrm{Cr}$ (VI). Sci Total Environ. 2020;710:135546.

64. Li B, Huang C, Yang X. Preparation and characterization of electrospun wool keratin/polyethylene oxide nanofibers for air filtration applications. Dig J Nanomater Biostruct. 2017;12:293-301.

65. Shen B, Zhang D, Wei Y, Zhao Z, Ma X, Zhao X, Wang S, Yang W. Preparation of Ag doped keratin/PA6 nanofiber membrane with enhanced air filtration and antimicrobial properties. Polymers (Basel). 2019;11(9):1511.

66. Barba C, Martí M, Roddick-Lanzilotta A, Manich A, Carilla J, Parra JL, Coderch L. Effect of wool keratin proteins and peptides on hair water sorption kinetics. J Therm Anal Calorim. 2010;102(1):43-8.

67. Barba C, Mendez S, Roddick-Lanzilotta A, Kelly R, Parra JL, Coderch L. Cosmetic effectiveness of topically applied hydrolysed keratin peptides and lipids derived from wool. Skin Res Technol. 2008;14(2):243-8.

68. Bayramoglu EE, Yorgancioglu A, Yeldiyar G, Onem E. Extraction of keratin from unhairing wastes of goat skin and creating new emulsion formulation containing keratin and calendula flower (Calendula officinalis L.). J Am Leather Chem Assoc. 2014;109(2):49-55.

69. Aluigi A, Sotgiu G, Torreggiani A, Guerrini A, Orlandi VT, Corticelli F, Varchi G. Methylene Blue doped films of wool keratin with antimicrobial photodynamic activity. ACS Appl Mater Interfaces. 2015;7(31):17416-24.

70. Zhong X, Li R, Wang Z, Wang W, Yu D. Eco-fabrication of antibacterial nanofibrous membrane with high moisture permeability from wasted wool fabrics. Waste Manag. 2020;102:404-11.

71. Ozaki Y, Takagi Y, Mori H, Hara M. Porous hydrogel of wool keratin prepared by a novel method: an extraction with guanidine/2-mercaptoethanol solution followed by a dialysis. Mater Sci Eng C Mater Biol Appl. 2014;42: 146-54.

72. Ferroni C, Sotgiu G, Sagnella A, Varchi G, Guerrini A, Giuri D, Polo E, Orlandi VT, Marras E, Gariboldi M, Monti E, Aluigi A. Wool keratin 3D scaffolds with light-triggered antimicrobial activity. Biomacromolecules. 2016;17(9):2882-90.

73. Fernandez-d'Arlas B. Tough and functional cross-linked bioplastics from sheep wool keratin. Sci Rep. 2019;9(1):14810

74. Kumar SL, Anandhavelu S, Swathy M. Preparation and characterization of goat hoof keratin/gelatin/sodium alginate base biofilm for tissue engineering application. Integr Ferroelectr. 2019;202(1):1-12.

75. Fortunati E, Aluigi A, Armentano I, Morena F, Emiliani C, Martino S, Santulli C, Torre L, Kenny JM, Puglia D. Keratins extracted from Merino wool and Brown Alpaca fibres: thermal, mechanical and biological properties of PLLA based biocomposites. Mater Sci Eng C Mater Biol Appl. 2015;47:394-406.

76. Cruz-Maya I, Guarino V, Almaguer-Flores A, Alvarez-Perez MA, Varesano A, Vineis C. Highly polydisperse keratin rich nanofibers: scaffold design and in vitro characterization. J Biomed Mater Res A. 2019;107(8):1803-13.

77. Wu P, Dai X, Chen K, Li R, Xing Y. Fabrication of regenerated wool keratin/ polycaprolactone nanofiber membranes for cell culture. Int J Biol Macromol. 2018;114:1168-73.

78. Zhang H, Ma H, Zhang R, Wang K, Liu J. Construction and characterization of antibacterial PLGA/wool keratin/ornidazole composite membranes for periodontal guided tissue regeneration. J Biomater Appl. 2020;34(9):1267-81.

79. Giuri D, Barbalinardo M, Sotgiu G, Zamboni R, Nocchetti M, Donnadio A, Corticelli F, Valle F, Gennari CGM, Selmin F, Posati T, Aluigi A. Nano-hybrid electrospun non-woven mats made of wool keratin and hydrotalcites as potential bio-active wound dressings. Nanoscale. 2019;11(13):6422-30.

80. Wang $X, X u$ W, Wang $X$. Characterization of hot-pressed films from superfine wool powder. J Appl Polym Sci. 2008;108(5):2852-6.

\section{Publisher's Note}

Springer Nature remains neutral with regard to jurisdictional claims in published maps and institutional affiliations. 